\title{
Phosphate-control adherence in hemodialysis patients: current perspectives
}

REVIEW

This article was published in the following Dove Press journal:

Patient Preference and Adherence

\author{
Ebele M Umeukeje ${ }^{1-3}$ \\ Amanda S Mixon 3,4 \\ Kerri L Cavanaugh ${ }^{1-3}$ \\ 'Vanderbilt Center for Kidney \\ Disease, Nashville, TN, USA; '2Division \\ of Nephrology, Department of \\ Medicine, Vanderbilt University \\ Medical Center, Nashville TN, USA; \\ ${ }^{3}$ Vanderbilt Center for Health \\ Services Research, Nashville, TN, \\ USA; ${ }^{4}$ Section of Hospital Medicine, \\ Vanderbilt University Medical Center, \\ Nashville, TN, USA
}

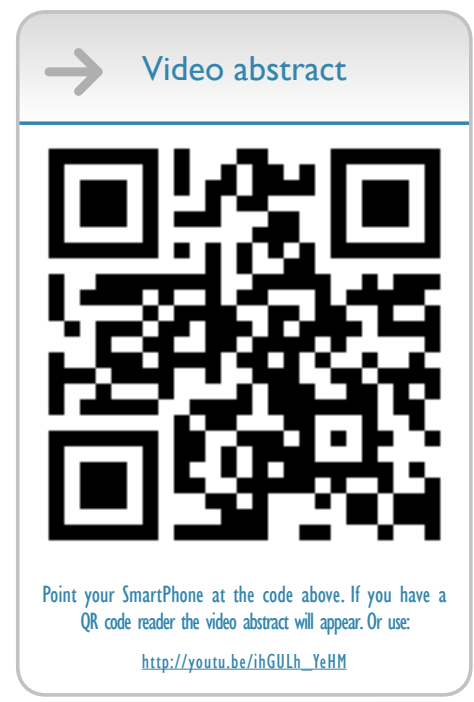

Correspondence: Ebele M Umeukeje Division of Nephrology, Department of Medicine, Vanderbilt University Medical Center, II6I 2 Ist Avenue South, MCN S-3223, Nashville, TN 37232, USA Email ebele.m.umeukeje@vanderbilt.edu
Objectives: This review summarizes factors relevant for adherence to phosphate-control strategies in dialysis patients, and discusses interventions to overcome related challenges.

Methods: A literature search including the terms "phosphorus", "phosphorus control", "hemodialysis", "phosphate binder medications", "phosphorus diet", "adherence", and "nonadherence" was undertaken using PubMed, PsycInfo, CINAHL, and Embase.

Results: Hyperphosphatemia is associated with cardiovascular and all-cause mortality in dialysis patients. Management of hyperphosphatemia depends on phosphate binder medication therapy, a low-phosphorus diet, and dialysis. Phosphate binder therapy is associated with a survival benefit. Dietary restriction is complex because of the need to maintain adequate protein intake and, alone, is insufficient for phosphorus control. Similarly, conventional hemodialysis alone is insufficient for phosphorus control due to the kinetics of dialytic phosphorus removal. Thus, all three treatment approaches are important contributors, with dietary restriction and dialysis as adjuncts to the requisite phosphate binder therapy. Phosphate-control adherence rates are suboptimal and are influenced directly by patient, provider, and phosphorus-control strategyrelated factors. Psychosocial factors have been implicated as influential "drivers" of adherence behaviors in dialysis patients, and factors based on self-motivation associate directly with adherence behavior. Higher-risk subgroups of nonadherent patients include younger dialysis patients and non-whites. Provider attitudes may be important - yet unaddressed - determinants of adherence behaviors of dialysis patients.

Conclusion: Adherence to phosphate binders, low-phosphorus diet, and dialysis prescription is suboptimal. Multicomponent strategies that concurrently address therapy-related factors such as side effects, patient factors targeting self-motivation, and provider factors to improve attitudes and delivery of culturally sensitive care show the most promise for long-term control of phosphorus levels. Moreover, it will be important to identify patients at highest risk for lack of control, and for programs to be ready to deliver flexible person-centered strategies through training and dedicated resources to align with the needs of all patients.

Keywords: hyperphosphatemia, adherence, phosphorus binders, low-phosphorus diet, dialysis

\section{Plain language summary}

Management of end-stage renal disease (ESRD) is complicated by hyperphosphatemia. This is the accumulation of phosphorus in the body due to the inability of dialysis patients to excrete phosphorus. This increases the risk of spontaneous bone fractures from abnormal mineral metabolism and risk of death from cardiovascular disease. Management of hyperphosphatemia depends on three approaches: use of medications known as phosphate binders, dietary phosphorus restriction, and removal of phosphorus through dialysis. Adherence to each of these approaches is a challenge for dialysis patients due to medication- or dialysis-treatment-associated burden, complexity of the diet, as well as patient-specific factors. Patient factors associated with phosphate-control adherence behaviors include age, gender, and race. In preliminary research, 
psychosocial autonomy-centered or self-motivation patient factors contribute to phosphorus-control adherence, and suggest that aligning with a person's value system may be the key to optimizing medication, diet, and dialysis care. Existing strategies to improve phosphate control include educational and behavioral interventions delivered by multidisciplinary dialysis providers. Emerging research implicates that dialysis providers have varying attitudes and poor perceptions of their support of self-motivation in dialysis patients for adherence to prescribed phosphate binder medication therapy. Improvement in phosphorus-control adherence will require enhanced provider-level training strategies integrated into existing patient-level interventions, with a focused effort to identify patients at high risk of nonadherence who may benefit from more personalized solutions.

\section{Introduction}

Hyperphosphatemia is common in end-stage renal disease (ESRD) because of impaired renal phosphate excretion. ${ }^{1}$ It is a critical component of mineral and bone disease (MBD) that increases the risk of fractures and osteoporosis, ${ }^{2}$ and is associated with greater cardiovascular and all-cause mortality in dialysis patients. ${ }^{3}$ Hyperphosphatemia may be effectively managed with phosphate binder medication therapy, dietary restriction, and dialysis prescription. ${ }^{1}$

Phosphate binder medication therapy is the cornerstone of therapeutic management in hyperphosphatemia, ${ }^{4}$ and it has been associated with survival benefits. The existing evidence, although robust, is from observational studies, ${ }^{5}$ and this could be a possible opportunity for a pragmatic trial design in the future. ${ }^{6}$ Optimization of phosphate binder use by patients with ESRD to achieve target serum phosphorus levels toward the normal range of $3.5-5.5 \mathrm{mg} / \mathrm{dL}$ is of utmost importance to minimize morbidity and mortality risks. ${ }^{7,8}$ However, it is estimated that up to $74 \%$ of ESRD patients are noncompliant to phosphate binder medication therapy. ${ }^{9,10}$ Challenges to adherence include 1) medicationrelated factors such as high pill counts, complex adjustable schedules, adverse side effects, and financial burden $;^{11}$ 2) patient-specific factors such as limited knowledge about the importance of taking binder medications; ${ }^{11,12}$ 3) recurrent hospitalizations disrupting the usual daily approaches to binder medications, and concomitant comorbidities such as diabetes and hypertension compounding medication complexity and overall burden; ${ }^{12}$ and 4) provider-level factors related to educational and emotional support for patients. ${ }^{11}$

High dietary phosphorus intake and increased dietary phosphorus-to-protein ratio have been associated with mortality in ESRD. ${ }^{11}$ A low-phosphorus diet is insufficient to control the serum phosphorus level in the well-nourished
ESRD patient, and has not been associated with improved survival. ${ }^{13}$ Dietary phosphorus restriction is complex because it is challenging to maintain the adequate protein intake needed in ESRD patients to prevent malnutrition and simultaneously restrict phosphorus intake. Perhaps even more importantly, many processed foods contain a significant amount of phosphate additives that are are often undisclosed and difficult for patients to identify. ${ }^{11}$ In ESRD, the ideal daily phosphorus intake is $700 \mathrm{mg}$ /day; however, the usual intake commonly averages $1,000-2,000 \mathrm{mg} /$ day. ${ }^{14}$ Approximately $60 \%$ of the phosphorus is absorbed, ${ }^{15}$ which results in a significant daily excess of phosphorus. Adherence to a lowphosphorus diet could be as low as $43 \%,{ }^{16}$ and is influenced similarly by 1) diet-specific factors such as menu selections, impact of the diet on social outings, and acceptance of the diet by friends and family; ${ }^{16} 2$ ) patient factors such as depression, limited self-efficacy, and poor coping skills; ${ }^{16}$ and 3 ) provider factors including inadequate support, ${ }^{16}$ infrequent contact with dietitians, and conflicting phosphorus diet advice from different health professionals. ${ }^{17}$

Thrice-weekly conventional dialysis removes phosphorus in the range of 1,800-3,600 $\mathrm{mg}$ and, thus, does not provide enough clearance of the daily amount of ingested phosphorus to maintain balance. ${ }^{18}$ This is due to the kinetics of phosphorus removal during hemodialysis, whereby serum phosphorus levels plateau after an initial drop within the first 2 hours of treatment, followed by a rebound, resulting in up to $40 \%$ rise in serum phosphorus levels after dialysis. ${ }^{19}$ Dialysis treatments are complicated by nonadherence, and it is estimated that up to $35 \%$ of patients miss treatments entirely whereas another $32 \%$ shorten their treatment time. ${ }^{20}$ Reasons for nonadherence to the prescribed dose of dialysis include treatment- and patient-related factors. Dialysis vintage and schedule assignment, both, are associated with treatment nonadherence. ${ }^{21}$ Patient factors associated with dialysis treatment nonadherence include younger age $e^{21,22}$ and non-white race $^{23}$ as well as psychosocial factors including negatively perceived effects of kidney disease on daily life and lack of perceived control over future health. ${ }^{22}$ Nonadherence to the dialysis procedure contributes to significant morbidity and increases mortality risk - in part, due to uncontrolled mineral bone disease. ${ }^{9,24}$

There are unique drivers of adherence behaviors for medications, diet, and dialysis in the effort to control phosphorus, but there are also common themes that can be leveraged to simultaneously optimize all approaches. This review discusses current perspectives and challenges contributing to low adherence to phosphate control, and examines 
effective and emerging strategies for patient-centered care with hemodialysis.

\section{Phosphate-control methods in hemodialysis patients Phosphate binder medication therapy}

An overview of phosphate binder medications is presented in Table 1. Phosphate binders regulate calcium-phosphate homeostasis and mitigate the metabolic abnormalities resulting from hyperphosphatemia. ${ }^{25}$ They prevent phosphate absorption from the gastrointestinal tract through varied mechanisms. These medications can be broadly classified into 1) calcium-based and 2) non-calcium-based phosphate binders.

Calcium-based phosphate binders including calcium acetate, citrate, and carbonate dissociate in the gastrointestinal tract and bind phosphate to form insoluble precipitates. They are less expensive than the non-calcium binders, ${ }^{10}$ but are associated with greater risk of vascular calcification due to a positive calcium balance. ${ }^{26}$

Non-calcium-based binders include sevelamer, lanthanum, and iron-based binders (eg, ferric citrate and sucroferric oxyhydroxide). ${ }^{26}$ Sevelamer is an anion exchange resin that exchanges chloride ions for phosphate ions whereas lanthanum binds phosphate through its trivalent cation. Both are associated with gastrointestinal side effects such as abdominal bloating, diarrhea, and constipation. Lanthanum has a low pill burden compared to sevelamer. Sevelamer carbonate is available as a powder for patients who may benefit from a different formulation; ${ }^{11}$ however, patients often get tired of taking it and usually request a change of phosphate binder preparation. ${ }^{27}$ The pill form of sevelamer is comparatively large in size and, given its accompanying high pill burden, it requires the ingestion of large quantities of water. ${ }^{7}$

Iron-based phosphate binders include ferric citrate and sucroferric oxyhydroxide. Ferric citrate is partially absorbed and, therefore, is ideal for the management of hyperphosphatemia in patients who are also iron deficient; however, the citrate content increases the potential for aluminum absorption and possible toxicity. ${ }^{28}$ Sucroferric oxyhydroxide is better suited for dialysis patients who do not require iron supplementation and has the added benefit of low pill burden. ${ }^{28}$ Findings from a recent metaanalysis suggest that nicotinic acid, a major form of vitamin B3, may be a novel effective alternative or adjunct for lowering serum phosphorus concentrations in dialysis patients. ${ }^{29}$ It lowers the absorption of phosphorus from the gastrointestinal tract, has unique antilipemic effects, and warrants further investigation of its long-term safety and efficacy. ${ }^{29}$

Patient tolerance of different phosphate binders varies, and patient-reported reasons for discontinuation of these medications also vary by the type of binder. ${ }^{30}$ Patients with ESRD may be nonadherent to phosphate binder therapy because of the misconception that nonadherence results in no immediate symptoms or risks. ${ }^{10,11}$ A systematic review of nonadherence to medications in hemodialysis patients described medication side effects, pill burden, large tablet size, unpalatable taste, medication regimen complexity, difficulty opening the medication container, and prescription refilling as key contributors to nonadherence. ${ }^{12}$ These medication-based factors are particularly characteristic of phosphate binders and, therefore, represent targets for control strategies.

\section{Epidemiology of phosphate binder adherence}

Nonadherence to phosphate binders ranges from $13 \%$ to $99 \%$, with an average of $53 \% .^{12}$ This range is wide partly due to heterogeneity in the methods of characterizing nonadherence. ${ }^{12}$ Current methods of assessing nonadherence to phosphate binders include 1) subjective measures, 2) objective measures, and 3) biochemical assessment of serum phosphorus levels. Estimated rates of nonadherence, assessed by subjective and objective measures as well as biochemical assessment of serum phosphorus levels, are $48 \%, 78 \%$, and $29 \%$ respectively. $^{12}$

Subjective measures using validated scales $^{31,32}$ or non-validated scales or interviews ${ }^{33,34}$ are the most widely used methods of nonadherence assessment. ${ }^{12}$ Objective measures including pill count, ${ }^{35}$ bottle-use devices such as Medication Event Monitoring System (MEMS) caps ${ }^{36,37}$ and medication possession ratio $^{38}$ are the least utilized methods of assessment. ${ }^{12}$ The biochemical assessment of serum phosphorus levels is frequently conducted as a part of routine dialysis care, but is complicated by variable definitions of the upper limit of the acceptable range. ${ }^{31,39}$ Moreover, these assessment methods have been used in combination in the absence of universally agreed upon standards for assessment of phosphate binder adherence. $^{40}$

\section{KDIGO guidelines for phosphate binder use}

The Kidney Disease: Improving Global Outcomes (KDIGO) Clinical Practice guideline for the diagnosis, evaluation, prevention, and treatment of chronic kidney disease - Mineral 


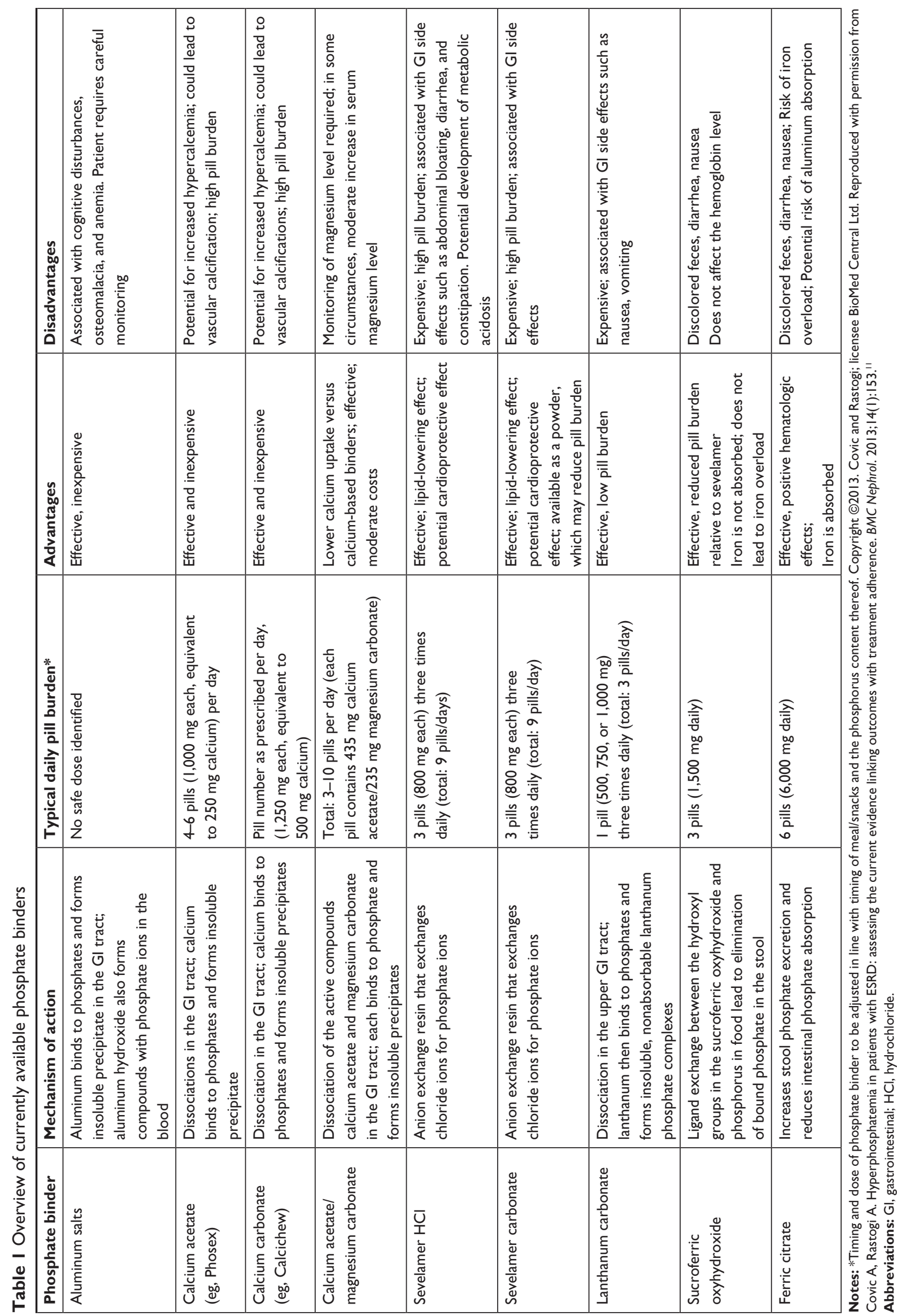


and Bone Disorder (CKD-MBD) was updated in 2017. The current recommendation for serum phosphorus control in dialysis patients is that decisions about phosphate-lowering treatment should be based on progressively or persistently elevated serum phosphate (Not graded), and elevated serum phosphorus levels should be lowered toward the normal range (3.5-5.5 mg/dL) (Grade $2 \mathrm{C}$ recommendation). However, implementation of this recommendation is challenging because of laboratory variability in the normal range of phosphorus and diurnal variations in serum phosphorus levels. Furthermore, the KDIGO guidelines recommend restricting the dose of calcium-based phosphate binders (Grade 2B recommendation). ${ }^{41}$

\section{Economics of phosphate binder use}

In the USA, phosphate binder use for US dialysis patients and patients with non-dialysis chronic kidney disease enrolled in Medicare Part D accounted for more than USD 1.5 billion in $2015 .{ }^{42}$ Phosphate binder-associated costs outweigh the costs associated with all other Part D-covered drugs for patients on dialysis. ${ }^{42}$ As of 2013, it cost Medicare five times as much for sevelamer carbonate and lanthanum carbonate, compared to calcium acetate, to achieve the same degree of phosphate control in a patient. ${ }^{42}$ When adjusted for the costs of binders, calcium binders have lower Medicare per member per month costs. ${ }^{43}$ Data from a recent systematic review suggest that calcium acetate is the most cost-effective therapy for first-line use in dialysis patients, although these conclusions were limited due to the heterogeneity of study quality. ${ }^{44}$

The enormous costs associated with the use of phosphate binders in dialysis patients in the absence of conclusive evidence of their impact on end points has been a source of controversy. ${ }^{42}$ There is controversy over the best way to determine the most cost-effective phosphate binder therapy, and much of the debate is due to the quality of existing data. One approach could be to look at overall expenses. It has been suggested that sevelamer is associated with a lower risk of stroke ${ }^{45}$ as well as reduced Medicare inpatient and total costs as compared with calcium-based binders, which makes it more cost effective overall. ${ }^{43}$ This continues to be a source of debate and may contribute to mixed messaging to patients about risks/benefits of the various choices.

\section{Factors affecting phosphate binder adherence Medication factors}

Multiple factors have been implicated in nonadherence to phosphate binders (Table 2). Medication-related factors responsible for nonadherence to phosphate binders are well studied, and the most commonly acknowledged is pill burden. Phosphate binders are often the single largest contributor to the excessive pill burden for dialysis patients, constituting half of their daily pill burden. ${ }^{35}$ Dialysis patients take a mean $11 \pm 4$ medications, with a median daily pill intake of 19 (interquartile range: 12). ${ }^{11}$ The total number of phosphate binders prescribed ${ }^{46}$ and total pill burden for other chronic conditions are associated with nonadherence to phosphate binders. ${ }^{35,47,43}$ The frequency of dosing of phosphate binders with all food intake, including meals, beverages, and snacks, increases its complexity and worsens adherence. ${ }^{12,47}$ Unfortunately, nonadherence leads to poorer phosphate control and results in an increase in the number of prescribed tablets. ${ }^{10}$ In addition to pill burden, the form, taste, and side effects - as discussed earlier - are also associated with nonadherence to these medications. ${ }^{46}$

\section{Patient factors}

Patient-related factors associated with phosphate binder nonadherence $^{12}$ include 1) sociodemographic and 2) psychosocial variables. Younger age $\mathrm{e}^{10,12,31-33,46-49}$ has been most consistently linked to phosphate binder nonadherence. Perhaps, younger people are prioritizing other activities over their health ${ }^{50}$ or, alternatively, they may be more willing to report nonadherence than older patients. ${ }^{10}$

Non-Caucasian race ${ }^{12,23,32,36,37,49}$ has been associated with phosphate binder nonadherence (odds ratio [OR 0.76]; $p<0.05$ ) ${ }^{49}$ and may be confounded by lower socioeconomic status. ${ }^{50}$ Other sociodemographic variables associated with phosphate binder nonadherence include lack of marital support ${ }^{12,52,53}$ (OR $1.21 ; p<0.05)^{49}$ and unemployment ${ }^{12,52}$ (OR 1.21; $\left.p<0.05\right)$, ${ }^{49}$ although findings across studies are not consistent.

Psychosocial factors have been identified as the most influential and potentially modifiable determinants of phosphate binder nonadherence (Figure 1). These include 1) patients' health beliefs and 2) social support related to hyperphosphatemia treatment. ${ }^{10}$ These health beliefs include concerns about the potential side effects of phosphate binders $(\mathrm{OR}=3.17 ; 95 \% \mathrm{CI}: 1.87-5.37 ; p<0.001){ }^{32}$ reduced beliefs in personal need for phosphate binder medications $(\mathrm{OR}=0.34 ; 95 \% \mathrm{CI}: 0.14-0.83 ; p<0.05){ }^{32}$ and low selfefficacy or perceived competence of taking phosphate binders $(t(71)=2.55, p<0.02) .{ }^{54}$ Knowledge about the purpose of phosphate binders has been found to be an important factor influencing adherence $(r=0.22 ; p<0.05) .{ }^{55}$ However, knowledge of treatment instructions does not correlate with adherence, suggesting that knowledge alone is insufficient to drive adherence to phosphate binders. ${ }^{10}$ 
Table 2 Factors associated with nonadherence and summary of relevant associations $(\mathrm{N}=38)$

\begin{tabular}{|c|c|c|c|c|}
\hline \multirow[t]{2}{*}{ Factors } & \multirow{2}{*}{$\begin{array}{l}\text { No of } \\
\text { studies }\end{array}$} & \multicolumn{3}{|c|}{ Significant association with measures of nonadherence ${ }^{a}$} \\
\hline & & $\begin{array}{l}\text { Pre-dialysis } \\
\text { phosphorus }\end{array}$ & $\begin{array}{l}\text { Patient } \\
\text { self-report }\end{array}$ & $\begin{array}{l}\text { Pill count/medication } \\
\text { event monitoring system }\end{array}$ \\
\hline \multicolumn{5}{|l|}{ Sociodemographic variables } \\
\hline Age & 27 & & & \\
\hline Younger & & 8 & 8 & \\
\hline Older & & I & 2 & I \\
\hline Gender & 22 & & & \\
\hline Male & & & I & \\
\hline Female & & & 2 & \\
\hline Low education (high school) & 15 & & I & \\
\hline Ethnicity (non-Caucasian) & 7 & I & I & 2 \\
\hline Marital status (single, divorced, or widowed) & 6 & & 2 & \\
\hline Employment status (unemployed) & 6 & & I & \\
\hline Support from healthcare provider & 2 & & 2 & \\
\hline Family problems (illness interfering with family life) & 2 & & I & \\
\hline Smoker & I & I & & \\
\hline \multicolumn{5}{|l|}{ Clinical variables } \\
\hline Long-term on hemodialysis & 16 & & 3 & \\
\hline Comorbidity (DM, HTN) & 9 & I & 1 & \\
\hline Number of hospitalizations & 2 & & I & \\
\hline \multicolumn{5}{|l|}{ Psychosocial variables } \\
\hline Depressive symptoms & 6 & & 4 & \\
\hline Beliefs about medicine & 5 & & & \\
\hline Concern & & 1 & 2 & \\
\hline Benefit & & I & I & \\
\hline Necessity & & 1 & 3 & \\
\hline Necessity-concern differential score & & & 2 & \\
\hline Health locus of control ${ }^{b}$ & 3 & 2 & 1 & \\
\hline Autonomous & & & 1 & \\
\hline Doctors & & & 1 & \\
\hline Emotional representation & I & I & & \\
\hline \multicolumn{5}{|l|}{ Medication-related factors } \\
\hline Knowledge about medicine & 5 & I & I & \\
\hline Number of prescribed medicines & 3 & & & I \\
\hline Daily tablet count & 2 & 1 & I & \\
\hline Total number of PB prescribed & 2 & 1 & I & \\
\hline Total pill burden & 2 & & & \\
\hline Pill burden from PB & I & & & I \\
\hline PB equivalent dosage & I & & 1 & \\
\hline Regimen complexity (frequency and dosage) & I & I & & \\
\hline Drug coverage by insurance & I & & & I \\
\hline Healthcare cost (inpatient) & I & & & I \\
\hline
\end{tabular}

Notes: aLevel of significance ( $p<0.05, p<0.01$, and $p<0.00 \mathrm{I}$ ) varies between studies. 'Defined as having high expectation that one's actions will have a causal relationship with the consequences produced. Copyright (2) 20I5. PLOS. Reproduced from Ghimire S, Castelino RL, Lioufas NM, Peterson GM, Zaidi ST. Nonadherence to medication therapy in haemodialysis patients: a systematic review. PLoS One. 20I5;10(I2):e0I44I 19.12

Abbreviations: DM, diabetes mellitus; HD, hemodialysis; HTN, hypertension; PB, phosphate binders.

Whereas marital support may be associated with adherence, the support of other family and friends has not yet been demonstrated to have a significant impact on phosphate binder nonadherence. ${ }^{55}$ Rather, the patient's perception of illness and its disruption of their family life contributes significantly to phosphate binder nonadherence $(r=-0.35 ; p<0.05) .{ }^{55}$

Depressive symptoms, furthermore, have been linked to nonadherence to phosphate binder therapy $(\mathrm{OR}=1.11$;
95\% CI, $1.04-1.18 ; p=0.001) .52,56,57$ Factors such as forgetfulness, lack of interest, and monotony have been identified as contributing to nonadherence. ${ }^{12}$ Intentional phosphate binder nonadherence behavior exists in dialysis patients ${ }^{58}$ and, in order to understand it, it is important to understand the patients' personal values and level of motivation. This addresses the call for patient-centered care in dialysis management that aligns patients' values to their therapy 


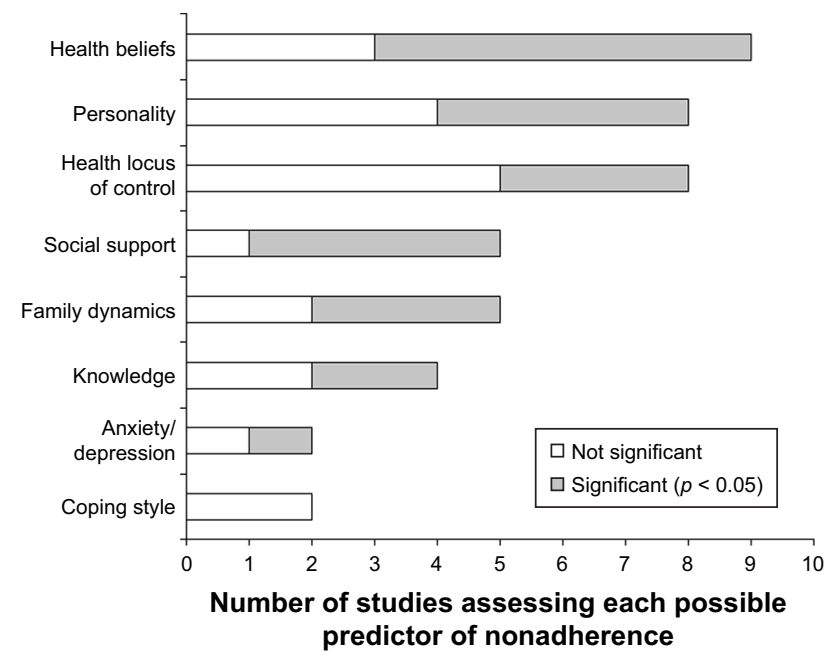

Figure I Psychosocial predictors of nonadherence to phosphate-binding medication assessed by two or more studies.

Note: (C2008. BioMed Central Ltd. Adapted from Karamanidou et al; licensee BioMed Central Ltd. Karamanidou C, Clatworthy J, Weinman J, Horne R. A systematic review of the prevalence and determinants of nonadherence to phosphate binding medication in patients with end-stage renal disease. BMC Nephrol. $2008 ; 9: 2 .^{10}$

while taking into account their side-effect and tolerability profiles. $^{59}$

Emerging research has identified that novel motivation and autonomy-centered factors are associated with phosphate binder nonadherence. These psychosocial factors are based on the self-determination theory (SDT), which posits that autonomy is an essential factor for achieving durable positive change. ${ }^{60}$ The SDT distinguishes between autonomous or self-motivated behavior and controlled behavior. It includes three unique psychosocial factors: autonomous regulation, autonomy support, and perceived competence. ${ }^{60}$ Higher autonomous regulation of phosphate binder therapy or more positive attitudes toward phosphate binder use has been associated with phosphate binder adherence. ${ }^{47,61} \mathrm{Simi}-$ larly, the perception of dialysis patients with regard to their providers' support of autonomy for phosphate binder therapy and patient empowerment are associated with adherence to binders. ${ }^{62}$ Moreover, perceived competence or self-efficacy has been associated with adherence to phosphate binder therapy ${ }^{63}$ These factors show great promise to better understand nonadherence as they are associated with self-reported phosphate binder adherence, ${ }^{61,62}$ and are potentially modifiable using patient-centered approaches, such as motivational interviewing. ${ }^{60,64}$

Racial differences in the relationship between these novel psychosocial factors, phosphate binder adherence, and phosphorus control suggest that they may be more important in non-whites. Non-white dialysis patients have a lower perception of provider support for phosphate binder adherence as compared to whites..$^{62}$ Furthermore, the association between autonomous regulation of phosphate binder therapy and serum phosphorus control is significant in non-whites $(\beta 95 \%$ CI: -0.38 [ -0.74 to -0.02$] ; p=0.04)$ but not in whites $(\beta$ $95 \%$ CI: 0.49 [ -0.00 to 0.99 ]; $p=0.05) .{ }^{61}$

\section{Phosphate binder adherence in the elderly}

Polypharmacy has been identified as a geriatric-related syndrome that is associated with medication nonadherence, ${ }^{51}$ and it is exacerbated when the regimen includes phosphate binders. There are currently no guidelines for achieving a balance between phosphate adherence and health-related quality of life for the elderly, or others with predicted poor survival. Therefore, the overarching principle for phosphatecontrol adherence is the delivery of patient-centered care, with individualization of phosphorus-control regimens to optimize health-related quality of life in the elderly.

\section{Provider factors}

The World Health Organization (WHO) highlights provider factors as important determinants of patient adherence to prescribed medication and emphasizes that 1) "patients need to be supported by providers, not blamed", 2) providers need to be able to assess adherence and factors that influence it, and 3) providers must be adequately trained in adherence management. ${ }^{65}$ Provider factors relevant to phosphate binder nonadherence have not been fully investigated. Interview and focus-group data from hemodialysis patients suggested the presence of adversarial interactions between dialysis patients and their providers that impact their adherence. ${ }^{66}$ In particular, dialysis providers do not 1) individualize their patients' care, but rather, deliver "assembly line" treatment, 2) recognize patients' knowledge based on their unique expertise on their bodies and experience gained from their chronic illness, or 3 ) engage in shared decision making. ${ }^{66}$

Provider attitudes have been shown to correlate with clinical outcomes. For instance, facilities with providers that have more positive attitudes toward transplants have better wait-listing performance ${ }^{67}$ The phosphate binder prescription patterns of dialysis providers are highly variable, and some dialysis units prescribed phosphate binders for a significantly smaller proportion of their dialysis patients. ${ }^{5}$ This suggests differences in the preferences of dialysis providers for, or attitudes toward, phosphate binders. ${ }^{5}$ Patients who positively characterize their interactions with their dialysis providers have a lower odds for nonadherence to phosphate binders $\left(\mathrm{OR}=0.52 ; 95 \%\right.$ CI, 0.30-0.90). ${ }^{33}$ Further, support by 
dialysis staff is associated with phosphate binder adherence $(r=0.20 ; p<0.05) .{ }^{55}$ Provider interventions show promise of a positive and sustained impact on medication adherence in dialysis patients.

\section{Dialysis treatment and hospitalizations affect medication adherence}

Longer duration on hemodialysis therapy of 5 years or more has been found to be the most consistent ESRD factor associated with phosphate binder nonadherence. ${ }^{17,47,68}$ Perhaps, the longer duration on hemodialysis leads to more boredom and frustration over the need for continued adherence to this challenging medication regimen. ${ }^{17}$ Another important consideration is the relatively frequent acute illnesses leading to hospitalization. This disrupts the rigorous routine of day-to-day phosphate binder medications and increases the perception of burden of therapy. ${ }^{47}$ In general, hospitalizations also have an adverse impact on medication adherence due to errors in medication reconciliation ${ }^{69}$ and patients' limited understanding of the post-discharge treatment plan..$^{70,71}$

\section{Interventions to improve phosphate binder adherence Patient education}

Knowledge about the rationale for phosphate binders is associated with improved patient adherence to phosphate binder therapy..$^{33}$ Patients need to be effectively educated about the risk associated with phosphate binder nonadherence and, specifically, its association with increased morbidity and mortality. ${ }^{14,19,72}$ Patient education about appropriate timing of dosing toward the end of each meal, as well as adjusting dosing to the phosphorus content of the food, is important to ensure binder efficacy. ${ }^{14}$

Effective approaches for phosphate binder education utilize tools such as pamphlets, posters, websites, and videos. ${ }^{14}$ However, the readability of many available patienteducation materials remains a concern, with text written at above the ninth-grade levels and formatting that does not meet standards for optimal usability. ${ }^{73,74}$ Delivery of education occurs in all formats, including face-to-face individual consultations, group education, telephonic consultations, and practical demonstrations ${ }^{19}$ such as lobby days in dialysis units. Individual educational sessions for binder adherence have the benefit of providing personalized education, but are resource and time intensive. Education in small groups promotes interaction among dialysis patient peers, and has been shown to improve phosphate binder knowledge, as well as adherence, when facilitated by a dietitian. ${ }^{19,75}$

\section{Incorporation of patient preferences}

Dosing regimens can be simplified by reducing pill burden and adjusting phosphate binder prescriptions to accommodate the patient's dialysis preferences. ${ }^{11}$ For instance, some patients favor calcium acetate gel caps over the tablets because of ease of swallowing ${ }^{76}$ whereas others have a preference for lanthanum because it requires fewer tablets. ${ }^{77}$ Adopting an individualized strategy that takes into account patient preferences with regard to phosphate binders resulted in significant improvement in intentional nonadherence, phosphorus control, and even costs related to phosphate binder use. ${ }^{27}$ This strategy empowers patients to request a change in binder type if they have had problems with the prescribed phosphate binders. It is recommended to offer alternate options to patients who object to a particular dosing method. ${ }^{14}$

\section{Patient empowerment techniques}

Counseling interventions that incorporate a cognitive or behavioral component could be most effective for improving phosphate binder adherence. ${ }^{19,78}$ Cognitive behavioral interventions are psychological strategies that focus on the association between thoughts, feelings, and emotions and assist patients in identifying and modifying negative thoughts, feelings, and behaviors to facilitate coping. They may include education or relaxation training delivered in different settings and formats. Motivational interviewing an autonomy-promoting style of communication - has been shown, in a small study, to improve phosphate binder adherence and phosphorus control. ${ }^{79}$ This style of communication effectively engages patients to focus on a behavioral change; resolve ambivalence; and make plans that are specific, measurable, action-based, realistic, and time-based (Table 3). Motivational interviewing uses strategies such as openended questions, affirmations, reflections, and summaries. ${ }^{80}$ Similarly, self-affirmation - which involves reflection on one's personal values in order to reduce resistance to healthrisk information - has been successfully used to improve adherence.$^{81}$ These patient empowerment techniques address the most influential factors of phosphate binder adherence, including beliefs and attitudes. ${ }^{10}$

Other potential novel approaches for patient empowerment in improving medication adherence include the use of electronic monitoring devices. These can be used to remind patients to take their medications at prescribed times and may be helpful in empowering patients to improve phosphate binder medication adherence. ${ }^{82}$ The Phosphate Education Program (PEP) is a novel program that incorporates patient 
Table 3 Motivational interviewing

\begin{tabular}{|c|c|c|c|}
\hline Motivational factor & Objective & Example & Follow-up \\
\hline I. Express empathy & $\begin{array}{l}\text { To establish rapport and avoid } \\
\text { resistance by demonstrating } \\
\text { understanding of the patient's } \\
\text { situation }\end{array}$ & $\begin{array}{l}\text { Patient expresses difficulty making all } \\
\text { these changes }\end{array}$ & $\begin{array}{l}\text { Remind the patient that current levels } \\
\text { put them at risk for more serious } \\
\text { diseases }\end{array}$ \\
\hline 2. Roll with resistance & $\begin{array}{l}\text { Avoid magnifying resistance by } \\
\text { allowing patient to explore their } \\
\text { barriers in a nonjudgmental } \\
\text { supportive manner }\end{array}$ & $\begin{array}{l}\text { Patient is reluctant to continue } \\
\text { medication since it is hard to remember } \\
\text { to take and they no longer feel unwell }\end{array}$ & $\begin{array}{l}\text { Ask the patient where they see } \\
\text { themselves in } 6 \text { months if they stop } \\
\text { taking the medication }\end{array}$ \\
\hline $\begin{array}{l}\text { 3. Elicit/provide } \\
\text { reminder/elicit }\end{array}$ & $\begin{array}{l}\text { Find out what the patient already } \\
\text { knows, fill in the gaps or correct } \\
\text { misconceptions, and explore how } \\
\text { the change you suggest will fit } \\
\text { into the patient's life }\end{array}$ & $\begin{array}{l}\text { Elicit: ask patient what they know about } \\
\text { managing their CKD }\end{array}$ & $\begin{array}{l}\text { Reminder: for example, to take statins } \\
\text { and closely monitor blood pressure } \\
\text { Elicit: "what do you think the biggest } \\
\text { barrier is for you right now in managing } \\
\text { this condition?" }\end{array}$ \\
\hline 4. Support autonomy & $\begin{array}{l}\text { To reduce resistance by assuring } \\
\text { patients you know you can't make } \\
\text { them do anything - it is their } \\
\text { choice }\end{array}$ & $\begin{array}{l}\text { Emphasize to patient that it is their } \\
\text { choice but as their doctor you are } \\
\text { concerned if they do not try medication }\end{array}$ & $\begin{array}{l}\text { Reiterate that it is the patient's choice } \\
\text { and they need to consider all the } \\
\text { options. Reassure patient that if they } \\
\text { do decide to try a particular medication } \\
\text { they will be regularly monitored } \\
\text { for side effects and dose adjusted } \\
\text { accordingly }\end{array}$ \\
\hline 5. Explore ambivalence & $\begin{array}{l}\text { Help patient consider pros and } \\
\text { cons of change in a relaxed yet } \\
\text { systematic manner }\end{array}$ & $\begin{array}{l}\text { Encourage a discussion about the pros } \\
\text { and cons, eg, eating egg whites as part of } \\
\text { a low-phosphorus diet }\end{array}$ & $\begin{array}{l}\text { Summarize current situation with the } \\
\text { patient and explain that the benefits } \\
\text { will outweigh the potential drawbacks } \\
\text { associated with an egg-white diet }\end{array}$ \\
\hline 6. Elicit change talk & $\begin{array}{l}\text { To evoke the patient's reasons, } \\
\text { desire, ability, and need for } \\
\text { change. This predicts increased } \\
\text { commitment to the lifestyle } \\
\text { change and good clinical outcome }\end{array}$ & $\begin{array}{l}\text { "What makes it important to you to start } \\
\text { an exercise program?" "What benefits } \\
\text { would come from losing weight?" "Why } \\
\text { do you want to quit smoking?" }\end{array}$ & $\begin{array}{l}\text { Remind patient of the benefits of } \\
\text { regular exercise and how well it made } \\
\text { them feel previously. These measures } \\
\text { will help patient become a good role } \\
\text { model for their children and allow them } \\
\text { to play sports together }\end{array}$ \\
\hline $\begin{array}{l}\text { 7. Develop an action } \\
\text { plan }\end{array}$ & $\begin{array}{l}\text { To help the patient develop a plan } \\
\text { that is realistic and suitable for } \\
\text { their life }\end{array}$ & $\begin{array}{l}\text { Enquire about the next step for the } \\
\text { patient. Ask what they think they can do } \\
\text { or are willing to do to improve health } \\
\text { and make a difference }\end{array}$ & $\begin{array}{l}\text { Motivate patient to follow plan and } \\
\text { reiterate the steps agreed, ie, eat more } \\
\text { vegetables, avoid fast foods, exercise } \\
\text { more, etc }\end{array}$ \\
\hline
\end{tabular}

Note: Copyright @2013. Dove Medical Press. Reproduced with permission from Kalantar-Zadeh K. Patient education for phosphorus management in chronic kidney disease. Patient Prefer Adherence. 2013;7:379-390. ${ }^{14}$

Abbreviation: CKD, chronic kidney disease.

empowerment by teaching patients how to estimate the phosphorus content of their food and adjust their phosphate binder therapy using a prescribed binder/unit ratio. ${ }^{83}$ This program equips patients for "eye-estimating" the phosphorus content of various foods to guide these real-time adjustments. It assigns similar phosphorus units to similar whole food groups whereby 1 phosphorus unit is equivalent to $100 \mathrm{mg}$ per serving. ${ }^{84}$ Informed by similar approaches in diabetes management, this approach seems promising; however, additional complexities of dietary recommendations for phosphorus management must be acknowledged.

\section{Dietary approaches to phosphorus control}

\section{Epidemiology of adherence to low-phosphorus diet}

An integrative review of studies on adherence to the renal diet reports a wide variation in dietary adherence. ${ }^{16}$ This is related to differences in how dietary adherence was measured ranging from subjective approaches involving self-reported adherence to indirect approaches using serum phosphorus levels or a combination of approaches. Adherence to a lowphosphorus diet from 15 studies of 12,571 ESRD patients ranges from $43 \%$ to $84 \%$ and the majority of these studies measured low phosphate dietary adherence using serum phosphorus levels. ${ }^{16}$ Interestingly, one study that measured the rates of low phosphate dietary adherence using two different methods reported a self-reported adherence rate of $33 \%$ as compared to an adherence rate of $44 \%$ when using serum phosphorus levels. ${ }^{85}$

\section{Types of dietary phosphorus}

Dietary phosphorus is obtained from three different sources: 1) organic phosphorus in plant foods; 2) organic phosphorus in animal protein; and 3) inorganic phosphorus from additives 
in processed food. ${ }^{14}$ The phosphorus content in plant foods has only $20 \%-40 \%$ bioavailability whereas the phosphorus content in animal protein has $40 \%-60 \%$ bioavailability. ${ }^{14}$ In sharp contrast, the phosphorus content from food additives has $100 \%$ bioavailability and has the most impact on hyperphosphatemia. ${ }^{14}$

\section{Phosphorus additives}

The "hidden" phosphorus content from phosphate additives found in processed foods ${ }^{86,87}$ increases the complexity of dietary phosphorus management. The presence of unlabeled phosphorus content in many foods, in addition to the wide array of foods high in natural phosphorus content, contributes to nonadherence to a low-phosphorus diet. More recently, emphasis has been placed on the reduction of phosphate additives by avoidance of processed, high-phosphorus protein sources. $^{14}$

\section{Balancing the protein-to-phosphorus ratio}

Dietary phosphorus restriction is complex because of the delicate balance between ensuring adequate protein intake and simultaneously restricting phosphorus intake. ${ }^{11,14}$ Achieving this balance is a high priority because higher protein intake (up to $1.4 \mathrm{~g} / \mathrm{kg} /$ day) has been linked to increased survival in dialysis patients, regardless of a simultaneous increase in serum phosphorus levels. ${ }^{88}$ Yet, higher levels of dietary phosphorus intake and higher dietary phosphorusto-protein ratios increase the 5-year mortality rates in hemodialysis. ${ }^{89}$ Interestingly, prior research has not yet demonstrated a survival benefit as a result of prescribed dietary phosphorus restriction. ${ }^{13}$ This may be explained, in part, because dietary phosphorus restriction is insufficient to reduce serum phosphorus load..$^{90}$ A daily low-phosphorus diet includes approximately $371 \mathrm{mg}$ of absorbed phosphorus each day. Therefore, phosphorus control inherently requires strategies in addition to dietary restriction. ${ }^{11,14}$

\section{Factors affecting adherence to low-phosphorus diet}

Table 4 presents factors affecting adherence to a low-phosphorus diet. A recent integrative review of dietary adherence in dialysis, including adherence to low-phosphorus diet, provides a detailed overview of contributory factors. ${ }^{16}$ Longer dialysis vintage has been associated with nonadherence to a low-phosphorus diet, ${ }^{16,17,49}$ perhaps due to the burden of managing such complex dietary recommendations for an extended time. ${ }^{16}$ Poor dietary knowledge has been linked to nonadherence to phosphorus-restricted diet. ${ }^{17,91,92}$

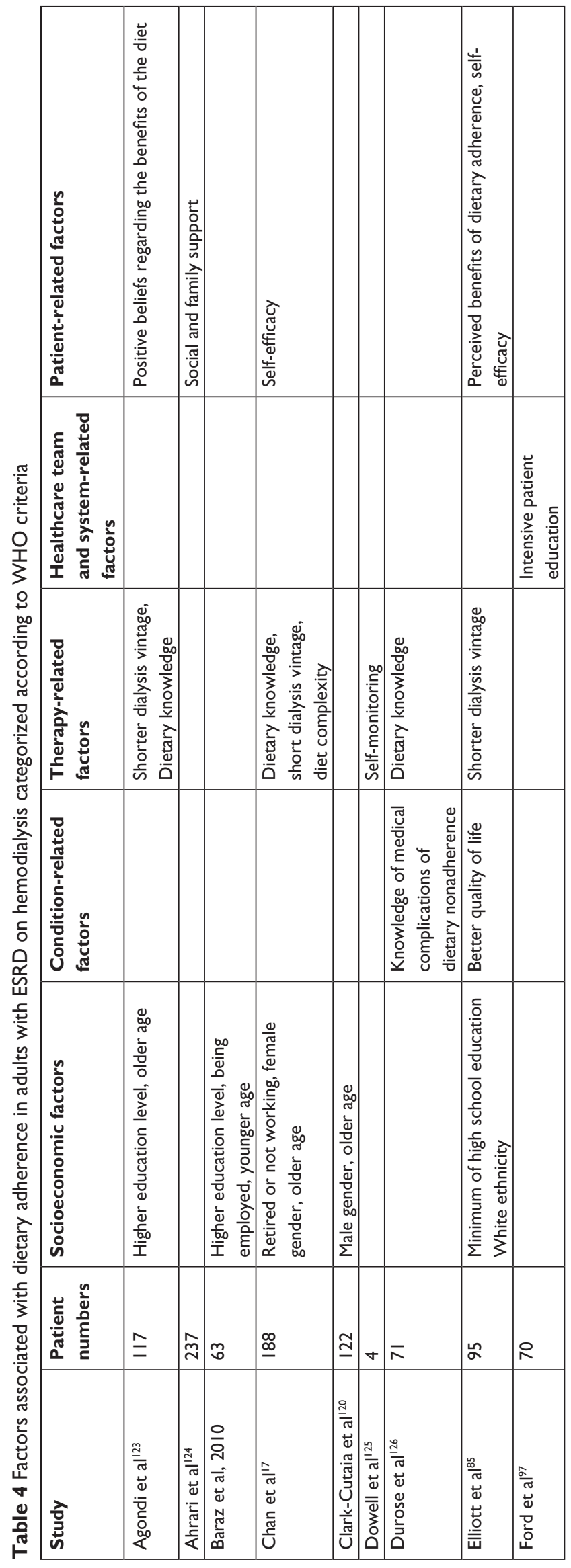




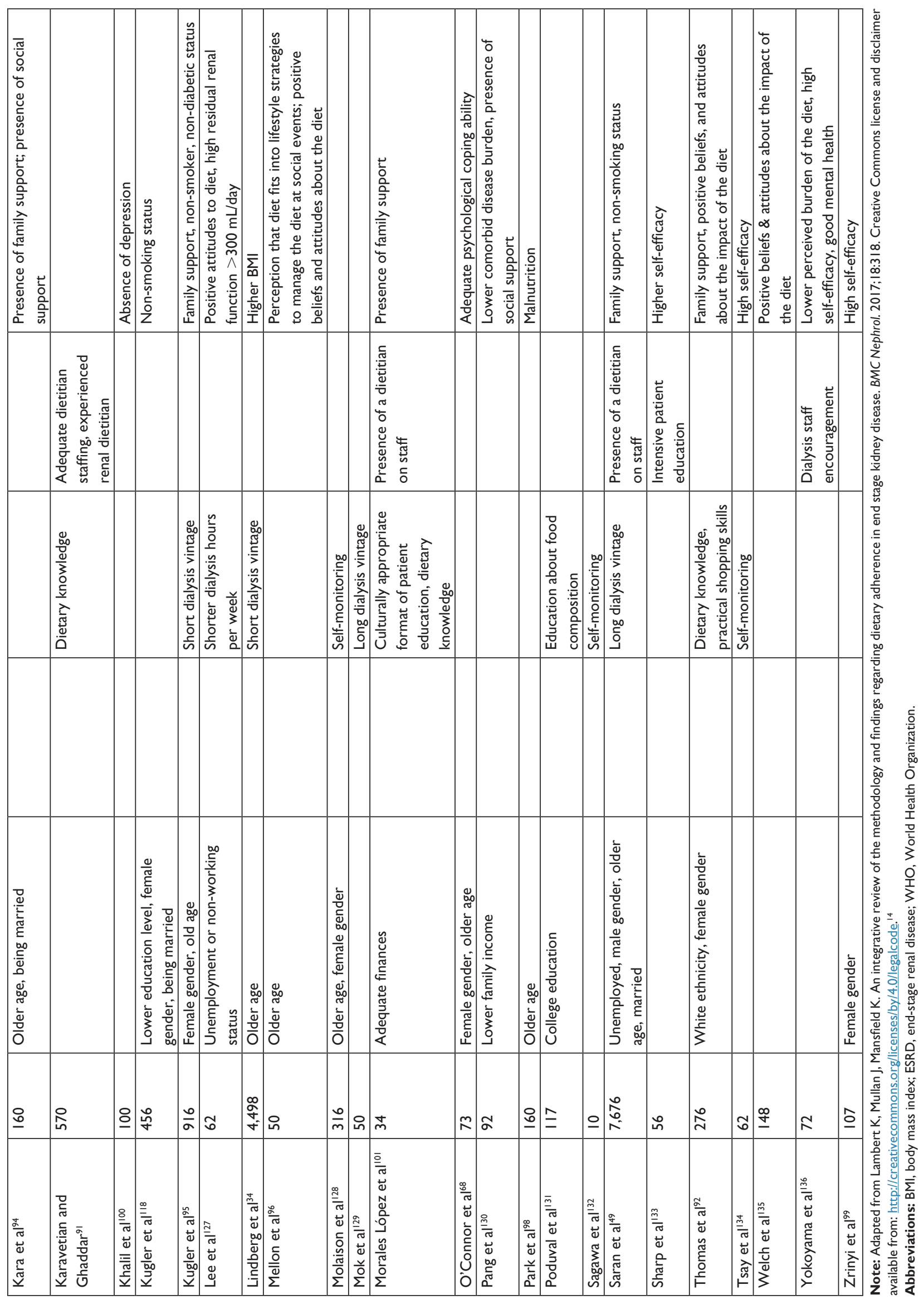


Furthermore, dialysis patients have acknowledged that the diet is challenging to incorporate into social occasions and dietary advice, preferably from renal dietitians or nephrologists, is of utmost importance. ${ }^{93}$

Patient factors associated with nonadherence to lowphosphorus diet include age, gender, race, and education level. ${ }^{16}$ Younger age $(r=0.19 ; p<0.05)$ and male gender are more likely to predict dietary nonadherence $(r=0.25 ; p<0.05)$. Nonwhites have been found to have more dietary nonadherence, ${ }^{85,92}$ and this may be driven by lower socioeconomic status. Employment status has been associated with dietary nonadherence in dialysis patients $(r=-0.36 ; p<0.01)$, and this may be because it is challenging to juggle the demands of the diet with the rigors of employment. Lower education level has been consistently associated with dietary nonadherence. ${ }^{17,94-98}$

Several psychosocial factors have been consistently associated with dietary nonadherence in dialysis. Negative beliefs and attitudes were strongly linked to dietary nonadherence. ${ }^{92,96}$ Moreover, patients with lower self-efficacy or depressive symptoms experienced dietary nonadherence. . $7,85,99,100^{\text {Poor }}$ coping skills have correlated with nonadherence to a lowphosphorus diet. ${ }^{68}$ Negative peer pressure or lack of acceptance of the prescribed diet by family or friends ${ }^{93}$ worsen dietary nonadherence.

Poor interaction between patients and dialysis providers is associated with dietary nonadherence, ${ }^{16}$ and conflicting dietary advice from different dialysis clinicians is also associated with nonadherence. ${ }^{17}$ Limited dietary education and support from renal dietitians ${ }^{49,91,101}$ was associated with dietary nonadherence, and this has largely been attributed to suboptimal staffing ratios. ${ }^{49,91}$

\section{Interventions to improve adherence to low-phosphorus diet}

Patient education

Effective education on dietary phosphorus restriction should include specific recommendations of foods with minimal inorganic phosphorus content, foods without phosphorus additives, low phosphorus-to-protein ratios, and adequate protein content (Table 5).${ }^{14}$ Patients need to understand that plant foods, animal-derived foods, and food additives have a range of low to high phosphorus bioavailability. ${ }^{14}$ Examples of food options that have the lowest phosphorus-to-protein ratio include non-dairy products and animal foods with high protein content such as egg whites. ${ }^{89}$ These food selections can effectively lower serum phosphorus level while simultaneously increasing the albumin level. ${ }^{102}$ In addition, education should include cooking methods that preserve protein content while reducing phosphorus content (eg, boiling chicken) to promote the low-phosphorus diet. . $^{14,103}$

Food fatigue or getting tired of eating the same allowed food has been identified as a larger problem than food intolerance or allergies in dietary management of chronic kidney disease, including ESRD. ${ }^{14}$ Food fatigue can be ameliorated by diversifying the diet to include additional low-phosphorus, high-protein food options such as poultry. ${ }^{14}$ Phosphate binder medication therapy, when taken effectively, also reduces food fatigue by permitting the patient's preferred mainstream foods while controlling their serum phosphorus levels..$^{14}$

Ideal patient education tools include information estimating the phosphorus content of food with glossaries of additives to guide the interpretation of food labels; comprehensive labeling of phosphorus additives; and use

Table 5 Strategies to improve control of dietary phosphorus intake and adherence to phosphate binders in ESRD

\begin{tabular}{ll}
\hline Patient education & Introduce education programs, led by nurses or other ancillary healthcare providers, focusing on the: \\
& physiologic role of phosphate and its presence in different foods \\
& 0 role of phosphate in ESRD-associated cardiovascular disease \\
& 0 importance of phosphate binders and their role in lowering serum phosphorus concentrations \\
& $\circ$ importance of dietary adherence \\
- Involve patients' families and friends in educational initiatives & - Tailor education to patients' lifestyle, environment, career, ethnicity, cultural background, and socioeconomic status \\
- Educate patients on appropriate food choices and provide training on preparing suitable meals \\
- Introduce initiatives such as the "Phosphate Education Program" which enable patients with hyperphosphatemia to \\
Patient \\
empowerment \\
- Reduce pill size and burden \\
- Improve properties & - Reduce associated adverse effects \\
of phosphate binders & - Introduce electronic monitoring devices, which may help patients remember to take their medications and support \\
& adherence
\end{tabular}

Note: Copyright ( 2013. @ Covic and Rastogi; licensee BioMed Central Ltd. Reproduced from Covic A, Rastogi A. Hyperphosphatemia in patients with ESRD: assessing the current evidence linking outcomes with treatment adherence. BMC Nephrol. 2013;14(I):153."

Abbreviation: ESRD, end-stage renal disease. 
of a "traffic light" scheme to classify foods based on low, intermediate, or high phosphorus content. ${ }^{104}$ Educational interventions to improve phosphorus control through dietary restriction have demonstrated improvements in patient knowledge, adherence to the low-phosphorus diet, as well as serum phosphorus levels. ${ }^{19,91,105}$ More recent educational initiatives, such as the Phosphate Education Program described earlier, empower patients to tailor the phosphorus content of food to their phosphate binder use per meal, leading to improved control of hyperphosphatemia. ${ }^{14,83,84}$

Dietitian-led interventions have been successful. ${ }^{75,106,107}$ Systematically delivered nursing instruction on low-phosphorus diet using a nursing instruction pamphlet, pictures, and reminder cards has also been shown to improve adherence, reduce serum phosphorus levels, and improve pruritus. ${ }^{108}$ Although comprehensive low-phosphorus dietary education, developed and delivered by dialysis nurses and physicians, was effective in improving serum phosphorus levels, ${ }^{109}$ dietitian involvement has been found to be more effective. ${ }^{109}$

\section{Behavioral interventions}

Behavioral interventions to improve dietary phosphate adherence also commonly employ counseling delivered by dietitians. ${ }^{19}$ Some interventions have been grounded in theoretical frameworks such as self-regulation theory ${ }^{91}$ and selfefficacy theory. ${ }^{110}$ Individualized self-management dietary counseling - especially in combination with patient educationimproves patient knowledge, dietary adherence, and serum phosphorus level. ${ }^{91}$ Use of a phosphate management protocol incorporating dietary counseling as well as patient education and pharmacotherapy delivered by a dialysis dietitian and a dialysis pharmacist, respectively, has led to greater improvement in serum phosphorus control compared to usual care. ${ }^{111}$ A motivational interviewing pilot study, focusing on dietary, medication, and dialysis attendance, demonstrated a positive impact on serum phosphorus control. ${ }^{79}$

\section{Other potential strategies}

Patients have expressed frustration about insufficient psychosocial support and information from providers that affects their self-care. ${ }^{112}$ Provider communication skills as well as the provider-patient relationship and interactions may have an impact on adherence to the prescribed low-phosphorus diet. ${ }^{16}$ Providers need to recognize that patients have limited self-efficacy ${ }^{17,85}$ and suboptimal attitudes ${ }^{92,93}$ that contribute to poor adherence to a low-phosphorus diet and are potential modifiable targets. Staffing ratios in the dialysis unit has been linked to adherence metrics and need to be optimized.
For instance, a ratio of no more than 60 dialysis patients per dietitian with monthly consultations has been shown to be more effective in improving phosphate binder adherence and serum phosphate control. ${ }^{14}$ Provider-level strategies may be an important opportunity to complement ongoing patient-focused interventions to improve dietary adherence in dialysis patients, and all members of the multidisciplinary team should be equipped to deliver phosphate binder adherence education and counseling. ${ }^{14}$

\section{Dialysis}

Conventional 4-hour thrice-weekly hemodialysis is limited in its ability to lower the phosphorus levels associated with the average dietary intake of phosphorus. ${ }^{19,113}$ Phosphorus removal through conventional hemodialysis occurs primarily during the first half of treatment, after which the serum phosphorus levels either plateau or even increase again (by up to $30 \%-40 \%$ ) due to a rebound effect. ${ }^{114}$ The daily phosphorus intake of dialysis patients can average $1,500 \mathrm{mg} /$ day or $10,500 \mathrm{mg} /$ week and, if $50 \%$ of that is absorbed, the phosphorus excess for removal by dialysis could be greater than $5,000 \mathrm{mg} .{ }^{15}$ However, conventional hemodialysis removes an average of 1,800-3,600 $\mathrm{mg}$ of phosphorus per week. Therefore, conventional hemodialysis alone is usually insufficient for phosphorus control. ${ }^{19}$ Optimal dialytic clearance of phosphorus is dependent on slow flow rates in addition to a longer dialysis time. Daily or extended nocturnal hemodialysis leads to greater phosphorus clearance compared with conventional thrice-weekly hemodialysis sessions. ${ }^{115}$

\section{Dialysis treatment nonadherence}

Dialysis treatment nonadherence is a significant problem. ${ }^{49}$ As much as $35 \%$ of patients miss treatments entirely whereas another $32 \%$ shorten their treatment time. ${ }^{20}$ In addition to its direct impact on hyperphosphatemia management, dialysis treatment nonadherence has been linked to increased hospitalizations ${ }^{116,117}$ and mortality. ${ }^{23,49}$ This high rate of treatment nonadherence has persisted and is linked to age, ${ }^{23,36}$ gender, ${ }^{118}$ marital status, ${ }^{118}$ ethnicity, ${ }^{23,119}$ and education ${ }^{118}$ as well as comorbidities and logistical barriers such as holidays that alter the dialysis unit scheduling. ${ }^{116}$ As with other chronic diseases requiring self-management, autonomy-centered psychosocial factors may be important, modifiable determinants of dialysis adherence. ${ }^{120}$ Deliberate multidisciplinary strategies to increase patient engagement in dialysis ${ }^{59,121,122}$ is increasingly recognized as a high-value opportunity to impact adherence behaviors and outcomes. 


\section{Conclusion}

Phosphate-control adherence is a fundamental component of care in dialysis, and adherence rates to phosphate binder therapy, low-phosphorus diet, and dialysis attendance remain suboptimal. Factors responsible for nonadherence include those related to the therapy (eg, medications, diet, dialysis); patient-specific factors including demographic, clinical, and psychosocial determinants, and provider-level factors. Psychosocial factors are the most influential determinants of adherence because they can be effectively modified using strategies that incorporate cognitive behavioral interventions to change negative beliefs, attitudes, and behaviors across treatment approaches to optimize phosphorus control. Provider-level factors are critical determinants of phosphatecontrol adherence in dialysis patients. Thus, provider-patient relationships must be enhanced by ensuring positive provider attitudes, adequate staffing ratio, and improved staff effectiveness by role clarification and training. All dialysis providers must be skilled in the delivery of culturally sensitive, patient-centered care using a novel combination of effective strategies and protocols. Optimal phosphate-control adherence rates will require multilevel interventions that recognize and address the preferences and unique attitudes of dialysis patients, enhance their self-regulation behaviors, and empower them to achieve sustained phosphate binder adherence.

\section{Acknowledgments}

The authors acknowledge the assistance of Heather Laferriere, MLIS, Library Liaison for Health Sciences at the Vanderbilt University Eskind Biomedical library for her support with detailed literature review from the selected databases.

\section{Disclosure}

Dr Umeukeje is supported by a BIRCWH K12 award (K12HDO43483-17 - PI: Katherine Hartmann). Dr Cavanaugh is supported by an NIH R01DK03935-01A1. Dr Mixon is supported by the Geriatric Research Education and Clinical Center (GRECC) at the VA Tennessee Valley Healthcare System. The authors report no other conflicts of interest in this work.

\section{References}

1. Malberti F. Hyperphosphataemia: treatment options. Drugs. 2013;73(7): 673-688.

2. Slatopolsky E, Gonzalez E, Martin K. Pathogenesis and treatment of renal osteodystrophy. Blood Purif. 2003;21(4-5):318-326.

3. Tentori F, Blayney MJ, Albert JM, et al. Mortality risk for dialysis patients with different levels of serum calcium, phosphorus, and PTH: the Dialysis Outcomes and Practice Patterns Study (DOPPS). Am J Kidney Dis. 2008;52(3):519-530.
4. Ketteler M, Biggar PH. Use of phosphate binders in chronic kidney disease. Curr Opin Nephrol Hypertens. 2013;22(4):413-420.

5. Lopes AA, Tong L, Thumma J, et al. Phosphate binder use and mortality among hemodialysis patients in the Dialysis Outcomes and Practice Patterns Study (DOPPS): evaluation of possible confounding by nutritional status. Am J Kidney Dis. 2012;60(1):90-101.

6. de Boer IH, Kovesdy CP, Navaneethan SD, et al; American Society of Nephrology Chronic Kidney Disease Advisory Group. Pragmatic clinical trials in CKD: opportunities and challenges. J Am Soc Nephrol. 2016;27(10):2948-2954.

7. Arenas MD, Malek T, Alvarez-Ude F, Gil MT, Moledous A, Reig-Ferrer A. Captores del fósforo: preferencias de los pacientes en hemodiálisis y su repercusión sobre el cumplimiento del tratamiento y el control del fósforo. [Phosphorus binders: preferences of patients on haemodialysis and its impact on treatment compliance and phosphorus control]. Nefrologia. 2010;30(5):522-530. Spanish [with English abstract].

8. Isakova T, Nickolas TL, Denburg M, et al. KDOQI US Commentary on the 2017 KDIGO Clinical Practice Guideline Update for the Diagnosis, Evaluation, Prevention, and Treatment of Chronic Kidney Disease-Mineral and Bone Disorder (CKD-MBD). Am J Kidney Dis. 2017;70(6):737-751.

9. Schmid H, Hartmann B, Schiffl H. Adherence to prescribed oral medication in adult patients undergoing chronic hemodialysis: a critical review of the literature. Eur J Med Res. 2009;14(5):185-190.

10. Karamanidou C, Clatworthy J, Weinman J, Horne R. A systematic review of the prevalence and determinants of nonadherence to phosphate binding medication in patients with end-stage renal disease. $B M C$ Nephrol. 2008;9:2.

11. Covic A, Rastogi A. Hyperphosphatemia in patients with ESRD: assessing the current evidence linking outcomes with treatment adherence. BMC Nephrol. 2013;14(1):153.

12. Ghimire S, Castelino RL, Lioufas NM, Peterson GM, Zaidi ST. Nonadherence to medication therapy in haemodialysis patients: a systematic review. PLoS One. 2015;10(12): 0144119.

13. Lynch KE, Lynch R, Curhan GC, Brunelli SM. Prescribed dietary phosphate restriction and survival among hemodialysis patients. Clin J Am Soc Nephrol. 2011;6(3):620-629.

14. Kalantar-Zadeh K. Patient education for phosphorus management in chronic kidney disease. Patient Prefer Adherence. 2013;7:379-390.

15. Waheed AA, Pedraza F, Lenz O, Isakova T. Phosphate control in endstage renal disease: barriers and opportunities. Nephrol Dial Transplant. 2013;28(12):2961-2968.

16. Lambert K, Mullan J, Mansfield K. An integrative review of the methodology and findings regarding dietary adherence in end stage kidney disease. BMC Nephrol. 2017;18:318.

17. Chan YM, Zalilah MS, Hii SZ. Determinants of compliance behaviours among patients undergoing hemodialysis in Malaysia. PLoS One. 2012;7(8):e41362.

18. Hou SH, Zhao J, Ellman CF, et al. Calcium and phosphorus fluxes during hemodialysis with low calcium dialysate. Am J Kidney Dis. 1991;18(2):217-224.

19. Milazi M, Bonner A, Douglas C. Effectiveness of educational or behavioral interventions on adherence to phosphate control in adults receiving hemodialysis: a systematic review. JBI Database System Rev Implement Rep. 2017;15(4):971-1010.

20. Denhaerynck K, Manhaeve D, Dobbels F, Garzoni D, Nolte C, De Geest S. Prevalence and consequences of nonadherence to hemodialysis regimens. Am J Crit Care. 2007;16(3):222-235; quiz 236.

21. Tohme F, Mor MK, Pena-Polanco J, et al. Predictors and outcomes of non-adherence in patients receiving maintenance hemodialysis. Int Urol Nephrol. 2017;49(8):1471-1479.

22. Kutner NG, Zhang R, McClellan WM, Cole SA. Psychosocial predictors of non-compliance in haemodialysis and peritoneal dialysis patients. Nephrol Dial Transplant. 2002;17(1):93-99.

23. Leggat JE Jr, Orzol SM, Hulbert-Shearon TE, et al. Noncompliance in hemodialysis: predictors and survival analysis. Am J Kidney Dis. 1998;32(1):139-145. 
24. O'Brien ME. Compliance behavior and long-term maintenance dialysis. Am J Kidney Dis. 1990;15(3):209-214.

25. Sekercioglu N, Thabane L, Diaz Martinez JP, et al. Comparative effectiveness of phosphate binders in patients with chronic kidney disease: a systematic review and network meta-analysis. PLoS One. 2016;11(6):e0156891.

26. Locatelli F, Del Vecchio L, Violo L, Pontoriero G. Phosphate binders for the treatment of hyperphosphatemia in chronic kidney disease patients on dialysis: a comparison of safety profiles. Expert Opin Drug Saf. 2014;13(5):551-561.

27. Arenas Jiménez MD, Parra Moncasi E, Álvarez-Ude Cotera F. A strategy based on patient preference improves the adherence and outcomes of phosphate binders in hemodialysis. Clin Nephrol. 2017;88(1):1-11.

28. Negri AL, Urena Torres PA. Iron-based phosphate binders: do they offer advantages over currently available phosphate binders? Clin Kidney J. 2015;8(2):161-167.

29. Liu X, Yang R, Dai B, Zhang H, Wang J, Ma N. Nicotinic acid and related compounds: a meta-analysis of their use for hyperphosphatemia in dialysis patients. Medicine (Baltimore). 2018;97(12):e0117.

30. Wang S, Anum EA, Ramakrishnan K, Alfieri T, Braunhofer P, Newsome B. Reasons for phosphate binder discontinuation vary by binder type. J Ren Nutr. 2014;24(2):105-109.

31. Wileman V, Farrington K, Wellsted D, Almond M, Davenport A, Chilcot J. Medication beliefs are associated with phosphate binder nonadherence in hyperphosphatemic haemodialysis patients. Br J Health Psychol. 2015;20(3):563-578.

32. Chater AM, Parham R, Riley S, Hutchison AJ, Horne R. Profiling patient attitudes to phosphate binding medication: a route to personalising treatment and adherence support. Psychol Health. 2014;29(12) 1407-1420.

33. Martins MT, Silva LF, Kraychete A, et al. Potentially modifiable factors associated with non-adherence to phosphate binder use in patients on hemodialysis. BMC Nephrol. 2013;14:208.

34. Lindberg M, Prütz KG, Lindberg P, Wikström B. Interdialytic weight gain and ultrafiltration rate in hemodialysis: lessons about fluid adherence from a national registry of clinical practice. Hemodial Int. 2009;13(2):181-188.

35. Chiu YW, Teitelbaum I, Misra M, de Leon EM, Adzize T, Mehrotra R. Pill burden, adherence, hyperphosphatemia, and quality of life in maintenance dialysis patients. Clin J Am Soc Nephrol. 2009;4(6) 1089-1096.

36. Curtin RB, Svarstad BL, Andress D, Keller T, Sacksteder P. Differences in older versus younger hemodialysis patients' noncompliance with oral medications. Geriatr Nephrol Urol. 1997;7(1):35-44.

37. Curtin RB, Svarstad BL, Keller TH. Hemodialysis patients' noncompliance with oral medications. ANNA J. 1999;26(3):307-316; discussion 317,335 .

38. Park H, Rascati KL, Lawson KA, Barner JC, Richards KM, Malone DC. Adherence and persistence to prescribed medication therapy among Medicare part $\mathrm{D}$ beneficiaries on dialysis: comparisons of benefit type and benefit phase. J Manag Care Spec Pharm. 2014;20(8):862-876.

39. Dolores Arenas M, Perez-Garcia R, Bennouna M, et al; Estudio COMQUELFOS. Improvement of therapeutic compliance in haemodialysis patients with poor phosphorus control and adherence to treatment with binders: COMQUELFOS study. Nefrologia. 2013;33(2):196-203.

40. Ghimire S, Peterson GM, Castelino RL, Jose MD, Zaidi STR. Medication regimen complexity and adherence in haemodialysis patients: an exploratory study. Am J Nephrol. 2016;43(5):318-324.

41. Ketteler M, Block GA, Evenepoel P, et al. Diagnosis, evaluation, prevention, and treatment of chronic kidney disease-mineral and bone disorder: Synopsis of the kidney disease: improving global outcomes 2017 clinical practice guideline update. Ann Intern Med. 2018;168(6):422-430.

42. St Peter WL, Wazny LD, Weinhandl ED. Phosphate-binder use in US dialysis patients: prevalence, costs, evidence, and policies. Am J Kidney Dis. 2018;71(2):246-253.

43. St Peter WL, Fan Q, Weinhandl E, Liu J. Economic evaluation of sevelamer versus calcium-based phosphate binders in hemodialysis patients: a secondary analysis using centers for Medicare \& Medicaid services data. Clin J Am Soc Nephrol. 2009;4(12):1954-1961.
44. Rizk R, Hiligsmann M, Karavetian M, Evers SM. Economic evaluations of interventions to manage hyperphosphataemia in adult haemodialysis patients: a systematic review. Nephrology (Carlton). 2016;21(3): 178-187.

45. Panichi V, Rosati A, Di Giorgio A, et al. A pharmacoeconomic analysis of phosphate binders cost-effectiveness in the RISCAVID study. Blood Purif. 2015;39(1-3):174-180.

46. Arenas MD, Malek T, Gil MT, Moledous A, Alvarez-Ude F, ReigFerrer A. Challenge of phosphorus control in hemodialysis patients: a problem of adherence? J Nephrol. 2010;23(5):525-534.

47. Neri L, Martini A, Andreucci VE, Gallieni M, Rey LA, Brancaccio D; MigliorDialisi Study Group. Regimen complexity and prescription adherence in dialysis patients. Am J Nephrol. 2011;34(1):71-76.

48. Wileman V, Chilcot J, Norton S, Hughes L, Wellsted D, Farrington K. Choosing not to take phosphate binders: the role of dialysis patients medication beliefs. Nephron Clin Pract. 2011;119(3):c205-c213.

49. Saran R, Bragg-Gresham JL, Rayner HC, et al. Nonadherence in hemodialysis: associations with mortality, hospitalization, and practice patterns in the DOPPS. Kidney Int. 2003;64(1):254-262.

50. Jin J, Sklar GE, Min Sen Oh V, Chuen Li S. Factors affecting therapeutic compliance: a review from the patient's perspective. Ther Clin Risk Manag. 2008;4(1):269-286.

51. Chao CT, Huang JW; COGENT (COhort of GEriatric Nephrology in NTUH) study group. Geriatric syndromes are potential determinants of the medication adherence status in prevalent dialysis patients. PeerJ. 2016;4:e2122.

52. Theofilou P. Medication adherence in Greek hemodialysis patients: the contribution of depression and health cognitions. Int J Behav Med. 2013;20(2):311-318.

53. Alkatheri AM, Alyousif SM, Alshabanah N, et al. Medication adherence among adult patients on hemodialysis. Saudi J Kidney Dis Transpl. 2014;25(4):762-768.

54. Christensen AJ, Wiebe JS, Benotsch EG, Lawton WJ. Perceived health competence, health locus of control, and patient adherence in renal dialysis. Cognit Ther Res. 1996;20(4):411-421.

55. Cummings KM, Becker MH, Kirscht JP, Levin NW. Psychosocial factors affecting adherence to medical regiments in a group of hemodialysis patients. Med Care. 1982;20(6):567-580.

56. Ossareh S, Tabrizian S, Zebarjadi M, Joodat RS. Prevalence of depression in maintenance hemodialysis patients and its correlation with adherence to medications. Iran J Kidney Dis. 2014;8(6):467-474.

57. Rosenthal Asher D, Ver Halen N, Cukor D. Depression and nonadherence predict mortality in hemodialysis treated end-stage renal disease patients. Hemodial Int. 2012;16(3):387-393.

58. Patel P, Antoniou S, Popat R. Unintentional non-adherence to phosphate binders. Eur J Hosp Pharm. 2015;22(1):18-22.

59. Cavanaugh KL. Prioritizing patient-centered care implementation and research for patients with kidney disease. Semin Dial. 2015;28(2): 131-140.

60. Deci EL, Ryan RM. Self-determination theory in health care and its relations to motivational interviewing: a few comments. Int $J$ Behav Nutr Phys Act. 2012;9:24.

61. Umeukeje EM, Merighi JR, Browne T, et al. Self-motivation Is associated with phosphorus control in end-stage renal disease. J Ren Nutr. 2015; 25(5):433-439.

62. Umeukeje EM, Merighi JR, Browne T, et al. Health care providers' support of patients' autonomy, phosphate medication adherence, race and gender in end stage renal disease. J Behav Med. 2016;39(6):1104-1114.

63. Umeukeje E, et al. Perceived competence is related to phosphorus control in end stage renal disease. NIDDK Network of Minority Research Investigators Conference; 20-22 April 2016; Bethesda, MA.

64. Miller WR, Rollnick S. Meeting in the middle: motivational interviewing and self-determination theory. Int Behav Nutr Phys Act. 2012;9:25.

65. Sabate E. Adherence to Long-term Therapies: Evidence for Action. Geneva: World Health Organization; 2003.

66. Allen D, Wainwright M, Hutchinson T. 'Non-compliance' as illness management: hemodialysis patients' descriptions of adversarial patientclinician interactions. Soc Sci Med. 2011;73(1):129-134. 
67. Gander J, Browne T, Plantinga L, et al. Dialysis facility transplant philosophy and access to kidney transplantation in the Southeast. Am J Nephrol. 2015;41(6):504-511.

68. O'Connor SM, Jardine AG, Millar K. The prediction of self-care behaviors in end-stage renal disease patients using Leventhal's SelfRegulatory Model. J Psychosom Res. 2008;65(2):191-200.

69. Omori DM, Potyk RP, Kroenke K. The adverse effects of hospitalization on drug regimens. Arch Intern Med. 1991;151(8):1562-1564.

70. Calkins DR, Davis RB, Reiley P, et al. Patient-physician communication at hospital discharge and patients' understanding of the postdischarge treatment plan. Arch Intern Med. 1997;157(9):1026-1030.

71. Ziaeian B, Araujo KL, Van Ness PH, Horwitz LI. Medication reconciliation accuracy and patient understanding of intended medication changes on hospital discharge. J Gen Intern Med. 2012;27(11): $1513-1520$

72. de Araujo LP, Figueiredo AE, d'Avila DO. Avaliação de programa de ensino-aprendizagem sobre metabolismo de cálcio e fósforo para pacientes em hemodiálise. [Evaluation of an educational program on calcium and phosphorus metabolism for patients on hemodialysis]. Rev Esc Enferm USP. 2010;44(4):928-932. Portuguese [with English abstract].

73. Tuot DS, Cavanaugh KL. Evaluating the merits of CKD patient educational materials: readability is necessary but not sufficient. Am J Kidney Dis. 2015;65(6):814-816.

74. Tuot DS, Davis E, Velasquez A, Banerjee T, Powe NR. Assessment of printed patient-educational materials for chronic kidney disease. Am J Nephrol. 2013;38(3):184-194.

75. Reddy V, Symes F, Sethi N, et al. Dietitian-led education program to improve phosphate control in a single-center hemodialysis population. J Ren Nutr. 2009;19(4):314-320.

76. Kaplan MR, Stashenko CL, Bledsoe AL, McGowan J. A preference study: calcium acetate tablets versus gelcaps in hemodialysis patients. Nephrol Nurs J. 2002;29(4):363-365.

77. Mehrotra R, Martin KJ, Fishbane S, Sprague SM, Zeig S, Anger M. Higher strength lanthanum carbonate provides serum phosphorus control with a low tablet burden and is preferred by patients and physicians: a multicenter study. Clin J Am Soc Nephrol. 2008;3(5): $1437-1445$

78. Matteson ML, Russell C. Interventions to improve hemodialysis adherence: a systematic review of randomized-controlled trials. Hemodial Int. 2010;14(4):370-382.

79. Russell CL, Cronk NJ, Herron M, et al. Motivational interviewing in dialysis adherence study (MIDAS). Nephrol Nurs J. 2011;38(3): 229-236.

80. Levensky ER, Forcehimes A, O'Donohue WT, Beitz K. Motivational interviewing: an evidence-based approach to counseling helps patients follow treatment recommendations. Am J Nurs. 2007;107(10):50-58; quiz 58-59.

81. Wileman V, Farrington K, Chilcot J, et al. Evidence that self-affirmation improves phosphate control in hemodialysis patients: a pilot cluster randomized controlled trial. Ann Behav Med. 2014;48(2):275-281.

82. Obrero Churillo T. Medication reminder systems: an adjunct technique in improving phosphate binder adherence. J Ren Nutr. 2012;22(1): e3-e9.

83. Kuhlmann MK. Management of hyperphosphatemia. Hemodial Int. 2006;10(4):338-345.

84. Kuhlmann MK, Hoechst S, Landthaler I. Patient empowerment in the management of hyperphosphatemia. Int J Artif Organs. 2007;30(11): $1008-1013$

85. Elliott JO, Ortman C, Almaani S, Lee YH, Jordan K. Understanding the associations between modifying factors, individual health beliefs, and hemodialysis patients' adherence to a low-phosphorus diet. $J$ Ren Nutr. 2015;25(2):111-120.

86. Uribarri J. Phosphorus additives in food and their effect in dialysis patients. Clin J Am Soc Nephrol. 2009;4(8):1290-1292.

87. Benini O, D'Alessandro C, Gianfaldoni D, Cupisti A. Extra-phosphate load from food additives in commonly eaten foods: a real and insidious danger for renal patients. $J$ Ren Nutr. 2011;21(4):303-308.
88. Shinaberger CS, Greenland S, Kopple JD, et al. Is controlling phosphorus by decreasing dietary protein intake beneficial or harmful in persons with chronic kidney disease? Am J Clin Nutr. 2008;88(6):1511-1518.

89. Noori N, Kalantar-Zadeh K, Kovesdy CP, Bross R, Benner D, Kopple JD. Association of dietary phosphorus intake and phosphorus to protein ratio with mortality in hemodialysis patients. Clin J Am Soc Nephrol. 2010;5(4):683-692.

90. Martin KJ, Gonzalez EA. Prevention and control of phosphate retention/hyperphosphatemia in CKD-MBD: what is normal, when to start, and how to treat? Clin J Am Soc Nephrol. 2011;6(2):440-446.

91. Karavetian M, Ghaddar S. Nutritional education for the management of osteodystrophy (nemo) in patients on haemodialysis: a randomised controlled trial. J Ren Care. 2013;39(1):19-30.

92. Thomas LK, Sargent RG, Michels PC, Richter DL, Valois RF, Moore CG. Identification of the factors associated with compliance to therapeutic diets in older adults with end stage renal disease. $J$ Ren Nutr. 2001;11(2):80-89.

93. Hollingdale R, Sutton D, Hart K. Facilitating dietary change in renal disease: investigating patients' perspectives. J Ren Care. 2008;34(3): 136-142.

94. Kara B, Caglar K, Kilic S. Nonadherence with diet and fluid restrictions and perceived social support in patients receiving hemodialysis. J Nurs Scholarsh. 2007;39(3):243-248.

95. Kugler C, Vlaminck H, Haverich A, Maes B. Nonadherence with diet and fluid restrictions among adults having hemodialysis. J Nurs Scholarsh. 2005;37(1):25-29.

96. Mellon L, Regan D, Curtis R. Factors influencing adherence among Irish haemodialysis patients. Patient Educ Couns. 2013;92(1):88-93.

97. Ford JC, Pope JF, Hunt AE, Gerald B. The effect of diet education on the laboratory values and knowledge of hemodialysis patients with hyperphosphatemia. J Ren Nutr. 2004;14(1):36-44.

98. Park KA, Choi-Kwon S, Sim YM, Kim SB. Comparison of dietary compliance and dietary knowledge between older and younger Korean hemodialysis patients. $J$ Ren Nutr. 2008;18(5):415-423.

99. Zrinyi M, Juhasz M, Balla J, et al. Dietary self-efficacy: determinant of compliance behaviours and biochemical outcomes in haemodialysis patients. Nephrol Dial Transplant. 2003;18(9):1869-1873.

100. Khalil AA, Frazier SK, Lennie TA, Sawaya BP. Depressive symptoms and dietary adherence in patients with end-stage renal disease. $J$ Ren Care. 2011;37(1):30-39.

101. Morales López C, Burrowes JD, Gizis F, Brommage D. Dietary adherence in Hispanic patients receiving hemodialysis. J Ren Nutr. 2007;17(2):138-147.

102. Taylor LM, Kalantar-Zadeh K, Markewich T, et al. Dietary egg whites for phosphorus control in maintenance haemodialysis patients: a pilot study. J Ren Care. 2011;37(1):16-24.

103. Cupisti A, D'Alessandro C, Baldi R, Barsotti G. Dietary habits and counseling focused on phosphate intake in hemodialysis patients with hyperphosphatemia. J Ren Nutr. 2004;14(4):220-225.

104. Ritz E, Hahn K, Ketteler M, Kuhlmann MK, Mann J. Phosphate additives in food - a health risk. Dtsch Arztebl Int. 2012;109(4):49-55.

105. Brogdon RM. A self-care educational intervention to improve knowledge of dietary phosphorus control in patients requiring hemodialysis: a pilot study. Nephrol Nurs J. 2013;40(4):313-318; quiz 319.

106. Mayne TJ, Benner D, Ricketts K, et al. Results of a pilot program to improve phosphorus outcomes in hemodialysis patients. J Ren Nutr. 2012;22(5):472-479.

107. Campbell KL, Ash S, Zabel R, McFarlane C, Juffs P, Bauer JD. Implementation of standardized nutrition guidelines by renal dietitians is associated with improved nutrition status. J Ren Nutr. 2009;19(2): $136-144$.

108. Cheng TY, Tarng DC, Liao YM, Lin PC. Effects of systematic nursing instruction on a low-phosphorus diet, serum phosphorus level and pruritus of patients on haemodialysis. J Clin Nurs. 2017;26(3-4):485-494.

109. Tsai WC, Yang JY, Luan CC, et al. Additional benefit of dietitian involvement in dialysis staffs-led diet education on uncontrolled hyperphosphatemia in hemodialysis patients. Clin Exp Nephrol. 2016;20(5): 815-821. 
110. Yun KS, Choi JY. [Effects of dietary program based on self-efficacy theory on dietary adherence, physical indices and quality of life for hemodialysis patients]. J Korean Acad Nurs. 2016;46(4):598-609. Korean [with English abstract].

111. Yokum D, Glass G, Cheung CF, Cunningham J, Fan S, Madden AM. Evaluation of a phosphate management protocol to achieve optimum serum phosphate levels in hemodialysis patients. JRen Nutr. 2008;18(6): 521-529.

112. Tong A, Sainsbury P, Chadban S, et al. Patients' experiences and perspectives of living with CKD. Am J Kidney Dis. 2009;53(4):689-700.

113. Lorenzo Sellares V, Torres Ramírez A. Management of hyperphosphataemia in dialysis patients: role of phosphate binders in the elderly. Drugs Aging. 2004;21(3):153-165.

114. Leypoldt JK. Kinetics of beta2-microglobulin and phosphate during hemodialysis: effects of treatment frequency and duration. Semin Dial. 2005;18(5):401-408.

115. Walsh M, Manns BJ, Klarenbach S, Tonelli M, Hemmelgarn B, Culleton B. The effects of nocturnal compared with conventional hemodialysis on mineral metabolism: a randomized-controlled trial. Hemodial Int. 2010;14(2):174-181.

116. Chan KE, Thadhani RI, Maddux FW. Adherence barriers to chronic dialysis in the United States. J Am Soc Nephrol. 2014;25(11): 2642-2648.

117. Vaiciuniene R, Kuzminskis V, Ziginskiene E, Skarupskiene I, Bumblyte IA. Adherence to treatment and hospitalization risk in hemodialysis patients. $J$ Nephrol. 2012;25(5):672-678.

118. Kugler C, Maeding I, Russell CL. Non-adherence in patients on chronic hemodialysis: an international comparison study. J Nephrol. 2011;24(3):366-375.

119. Christensen AJ, Benotsch EG, Wiebe JS, Lawton WJ. Coping with treatment-related stress: effects on patient adherence in hemodialysis. J Consult Clin Psychol. 1995;63(3):454-459.

120. Clark-Cutaia MN, Ren D, Hoffman LA, Burke LE, Sevick MA. Adherence to hemodialysis dietary sodium recommendations: influence of patient characteristics, self-efficacy, and perceived barriers. $J$ Ren Nutr. 2014;24(2):92-99.

121. Bear RA, Stockie S. Patient engagement and patient-centred care in the management of advanced chronic kidney disease and chronic kidney failure. Can J Kidney Health Dis. 2014;1:24.

122. O'Hare AM, Armistead N, Schrag WL, Diamond L, Moss AH. Patientcentered care: an opportunity to accomplish the "Three Aims" of the National Quality Strategy in the Medicare ESRD program. Clin J Am Soc Nephrol. 2014;9(12):2189-2194.
123. Agondi Rde F, Gallani MC, Rodrigues RC, Cornelio ME. Relationship between beliefs regarding a low salt diet in chronic renal failure patients on dialysis. J Ren Nutr. 2011;21(2):160-168.

124. Ahrari S, Moshki M, Bahrami M. The relationship between social support and adherence of dietary and fluids restrictions among hemodialysis patients in Iran. J Caring Sci. 2014;3(1):11-19.

125. Dowell SA, Welch JL. Use of electronic self-monitoring for food and fluid intake: a pilot study. Nephrol Nurs J. 2006;33(3):271-277.

126. Durose CL, Holdsworth M, Watson V, Przygrodzka F. Knowledge of dietary restrictions and the medical consequences of noncompliance by patients on hemodialysis are not predictive of dietary compliance. $J$ Am Diet Assoc. 2004;104(1):35-41.

127. Lee SH, Molassiotis A. Dietary and fluid compliance in Chinese hemodialysis patients. Int J Nurs Stud. 2002;39(7):695-704.

128. Molaison EF, Yadrick MK. Stages of change and fluid intake in dialysis patients. Patient Educ Couns. 2003;49(1):5-12.

129. Mok E, Tam B. Stressors and coping methods among chronic haemodialysis patients in Hong Kong. J Clin Nurs. 2001;10(4):503-511.

130. Pang SK, Ip WY, Chang AM. Psychosocial correlates of fluid compliance among Chinese haemodialysis patients. J Adv Nurs. 2001; 35(5):691-698.

131. Poduval RD, Wolgemuth C, Ferrell J, Hammes MS. Hyperphosphatemia in dialysis patients: is there a role for focused counseling? J Ren Nutr. 2003;13(3):219-223.

132. Sagawa M, Oka M, Chaboyer W. The utility of cognitive behavioural therapy on chronic haemodialysis patients' fluid intake: a preliminary examination. Int J Nurs Stud. 2003;40(4):367-373.

133. Sharp J, Wild MR, Gumley AI, Deighan CJ. A cognitive behavioral group approach to enhance adherence to hemodialysis fluid restrictions: a randomized controlled trial. Am J Kidney Dis. 2005;45(6) 1046-1057.

134. Tsay SL. Self-efficacy training for patients with end-stage renal disease. J Adv Nurs. 2003;43(4):370-375.

135. Welch JL. Hemodialysis patient beliefs by stage of fluid adherence Res Nurs Health. 2001;24:105-112.

136. Yokoyama Y, Suzukamo Y, Hotta O, et al. Dialysis staff encouragement and fluid control adherence in patients on hemodialysis. Nephrol Nurs J. 2009;36(3):289-297.
Patient Preference and Adherence

\section{Publish your work in this journal}

Patient Preference and Adherence is an international, peer-reviewed, open access journal that focuses on the growing importance of patient preference and adherence throughout the therapeutic continuum. Patient satisfaction, acceptability, quality of life, compliance, persistence and their role in developing new therapeutic modalities and compounds to optimize

\section{Dovepress}

clinical outcomes for existing disease states are major areas of interest for the journal. This journal has been accepted for indexing on PubMed Central. The manuscript management system is completely online and includes a very quick and fair peer-review system, which is all easy to use. Visit http://www. dovepress.com/testimonials.php to read real quotes from published authors. 